\title{
A novel inhibitor of Chlamydophila pneumoniae protein kinase $D$ (PknD) inhibits phosphorylation of $C d s D$ and suppresses bacterial
} replication

\author{
Dustin L Johnson ${ }^{1,2}$, Chris B Stone ${ }^{1,2}$, David C Bulir1,2, Brian K Coombes ${ }^{1,2}$ \\ and James B Mahony*1,2
}

\begin{abstract}
Address: ${ }^{1}$ MG DeGroote Institute for Infectious Disease Research and the Department of Pathology and Molecular Medicine, McMaster University, Ontario, Canada and ${ }^{2}$ The Father Sean O'Sullivan Research Centre, St Joseph's Healthcare, Hamilton, Canada

Email: Dustin L Johnson - johnsdl@mcmaster.ca; Chris B Stone - stonec@mcmaster.ca; David C Bulir - bulirdc@mcmaster.ca; Brian K Coombes - coombes@mcmaster.ca; James B Mahony* - mahonyj@mcmaster.ca

* Corresponding author
\end{abstract}

Published: 14 October 2009

BMC Microbiology 2009, 9:218 doi:10.1186/147|-2180-9-2/8

This article is available from: http://www.biomedcentral.com//47/-2/80/9/218

(c) 2009 Johnson et al; licensee BioMed Central Ltd.

This is an Open Access article distributed under the terms of the Creative Commons Attribution License (http://creativecommons.org/licenses/by/2.0), which permits unrestricted use, distribution, and reproduction in any medium, provided the original work is properly cited.

\begin{abstract}
Background: We have shown previously that Chlamydophila pneumoniae contains a dual-specific $\mathrm{Ser} / \mathrm{Thr}$ protein kinase that phosphorylates $\mathrm{CdsD}$, a structural component of the type III secretion apparatus. To further study the role of PknD in growth and development we sought to identify a PknD inhibitor to determine whether PknD activity is required for replication.
\end{abstract}

Results: Using an in vitro kinase assay we screened 80 known eukaryotic protein kinase inhibitors for activity against PknD and identified a 3'-pyridyl oxindole compound that inhibited PknD autophosphorylation and phosphorylation of CdsD. The PknD inhibitor significantly retarded the growth rate of $C$. pneumoniae as evidenced by the presence of very small inclusions with a reduced number of bacteria as seen by electron microscopy. These inclusions contained the normal replicative forms including elementary bodies (EB), intermediate bodies (IB) and reticulate bodies (RB), but lacked persistent bodies (PB), indicating that induction of persistence was not the cause of reduced chlamydial growth. Blind passage of $C$. pneumoniae grown in the presence of this PknD inhibitor for 72 or $84 \mathrm{hr}$ failed to produce inclusions, suggesting this compound blocks an essential step in the production of infectious chlamydial EB. The compound was not toxic to HeLa cells, did not block activation of the MEK/ERK pathway required for chlamydial invasion and did not block intracellular replication of either Chlamydia trachomatis serovar D or Salmonella enterica sv. Typhimurium suggesting that the inhibitory effect of the compound is specific for $C$. pneumoniae.

Conclusion: We have identified a 3'-pyridyl oxindole compound that inhibits the in vitro kinase activity of $C$. pneumoniae $P k n D$ and inhibits the growth and production of infectious $C$. pneumoniae progeny in HeLa cells. Together, these results suggest that PknD may play a key role in the developmental cycle of $C$. pneumoniae. 


\section{Background}

Chlamydophila pneumoniae is an important human respiratory pathogen that causes laryngitis, pharyngitis, bronchitis and community acquired pneumonia [1] and has been associated with exacerbation of asthma [2,3], atherosclerosis [4-6], arthritis [2,7], Alzheimer's disease [8,9] and Multiple Sclerosis [10-13]. The ability of C. pneumoniae to remain viable within lung macrophages [14-16] provides a mechanism for dissemination of Chlamydia to other anatomical sites that may include the arterial wall [17] and the brain. Rapid and successful treatment of C. pneumoniae respiratory infections is therefore important to ensure complete clearance of the bacteria in order to avoid infections elsewhere in the body. Antibiotics such as azithromycin, clarithromycin, erythromycin, and doxycycline have been used to treat $C$. pneumoniae respiratory infections [18]. However, clinical isolates of Chlamydia resistant to azithromycin and erythromycin have been reported [19], and some chlamydial species including $C$. pneumoniae develop resistance to antibiotics in vitro [2025]. Furthermore, sub-optimal concentrations of antibiotics in vivo may result in chlamydial persistence $[16,26]$, rendering the bacteria refractory to further antibiotic therapy $[27,28]$, and increasing the likelihood of Chlamydia persisting in the body for months or years [29,30]. Given that persistent chlamydial infections may lead to chronic conditions there is a need to develop novel anti-microbials to eradicate chlamydial infections.

All chlamydiae spp. exhibit a developmental cycle that begins when an infectious elementary body attaches to and invades a eukaryotic host cell. During invasion the EB becomes enveloped by the host cell plasma membrane, ultimately creating an intracellular vacuole known as an inclusion, within which the bacterium undergoes replication. The EB next transforms into a reticulate body, a developmental process that is characterized by reduction of EB outer membrane proteins [31-33] and DNA decondensation. RB are non-infectious, 2-5 times larger than EB and metabolically active. Division of RB occurs once every 2-3 hours for C. trachomatis and 6-7 hours for C. pneumoniae [34-36]. A hallmark of chlamydial replication is the expansion of the host cell-derived inclusion membrane to accommodate increasing numbers of bacteria. In response to an as yet unidentified signal, $\mathrm{RB}$ begin to asynchronously differentiate into infectious EB by transformation through the IB stage that contains partially condensed chromosomal DNA. The end of the developmental cycle occurs when EB are released from the host cell following inclusion lysis, or extrusion of the inclusion into neighbouring cells [37]. In addition to the three developmental forms seen during the chlamydial developmental cycle, Chlamydia may be induced to form persistent bodies, a morphological state not part of normal growth and development. The PB is an abnormally large form of chlamydia that occurs in response to interferon- $\gamma$ [27], antibiotics [26], or iron limitation [38], and is characterized by an inability to segregate into daughter cells after genomic DNA replication. The arrest of the developmental cycle at the $\mathrm{PB}$ stage can be reversed when the inducer stimulus in the case of iron deprivation is removed [38]. In addition to interferon- $\gamma$, and conventional antibiotics such as $\beta$-lactams and macrolides, other compounds exhibit bacteriostatic activity against Chlamydia in cell culture. These include selective cycloxygenase inhibitors, rottlerin and inhibitors of type III secretion [34,38-42]. Rottlerin is a pan-specific inhibitor of eukaryotic protein kinases and was recently shown to inhibit the growth of C. pneumoniae in HeLa cells [40]. Rottlerin may interfere with activation of the host MEK/ERK pathway which has been shown to be necessary for chlamydial cell invasion [43] and therefore indirectly cause inhibition of chlamydial growth. Alternatively, INP0007 (compound C1), INP0010, and INP0400, inhibitors of Yersinia type III secretion, may target a bacterial-specific factor related to the type III secretion system and directly abrogate chlamydial growth in eukaryotic cells $[39,41,44]$. The identification of novel targets may prove useful in the development of new antimicrobials effective against chlamydiae.

Chlamydial genomic studies have identified three Ser/Thr protein kinases, Pkn1, Pkn5, and PknD. Our laboratory has shown previously that C. pneumoniae PknD is a dualspecific protein kinase that autophosphorylates on threonine and tyrosine residues and phosphorylates serine and tyrosine residues of the FHA-2 domain of Cpn0712, a putative Yersinia YscD ortholog called CdsD [45]. In this report we show that a 3'-pyridyl oxindole compound, a known inhibitor of Janus kinase 3 (JAK3), inhibits $C$. pneumoniae PknD activity. This compound prevented PknD autophosphorylation and phosphorylation of CdsD, a type III secretion apparatus protein. When added to infected HeLa cells, the compound retarded C. pneumoniae growth and significantly reduced the amount of infectious C. pneumoniae produced suggesting that PknD plays an important role in chlamydial replication.

\section{Results \\ Identification of an inhibitor of C. pneumoniae PknD protein kinase activity}

We have recently shown that $C$. pneumoniae contains three Ser/Thr protein kinases [46] and that one of these, PknD, phosphorylates CdsD, a structural component of the type III secretion system (T3SS) [45]. In order to determine whether PknD plays an essential role in Chlamydia development, we screened an existing library of 80 small molecule kinase inhibitors, including inhibitors of eukaryotic receptor tyrosine kinases and atypical kinases, for their ability to inhibit PknD autophosphorylation in vitro. Recombinant GST-tagged PknD kinase domain (GST- 
PknD KD) was pre-incubated with $10 \mu \mathrm{M}$ of each compound and reactions initiated with the addition of kinase assay buffer containing $\mathrm{Mn}^{2+}$ and ATP. SDS-PAGE and Western blotting followed by autoradiography was used to visualize the extent of PknD autophosphorylation in the presence of each compound. Nine compounds (EMD designations: D7, E8, F4, F5, F6, F7, G5, H10, and H11) of the 80 tested exhibited some level of inhibition of PknD autophosphorylation when tested at $10 \mu \mathrm{M}$ (data not shown). Of these nine compounds only one, compound D7, a 3'-pyridyl oxindole, completely inhibited PknD autophosphorylation. Fig. 1A shows a dose response for PknD inhibition. At $1 \mu \mathrm{M}$ compound D7 reduced PknD autophosphorylation by greater than $50 \%$ (fig. 1A). Similar results were obtained with two different lots of the inhibitor. Compound D4, a pan-specific inhibitor of the Janus kinase (JAK) family, did not significantly inhibit PknD autophosphorylation at concentrations of 0.2 to $10 \mu \mathrm{M}$ (figs. $1 \mathrm{~A}$ and $1 \mathrm{~B}$ ). Similarly, two other JAK3 inhibitors, compounds D5 and D6, did not inhibit PknD autophosphorylation at concentrations of 1 or $10 \mu \mathrm{M}$ (fig. 1B).

Compound D7 is ATP competitive and therefore it has the potential to inhibit other chlamydial enzymes that utilize ATP as a substrate. To determine if compound D7 could inhibit a chlamydial ATPase, we examined its effect on the activity of CdsN, the T3SS ATPase of C. pneumoniae [47]. The activity of $\mathrm{CdsN}$ was $0.51 \pm 0.09$ and $0.43 \pm 0.06$ micromoles of phosphate $/ \mathrm{min} / \mathrm{mg}$ protein in the presence of $5 \mu \mathrm{M}$ and $100 \mu \mathrm{M}$ of compound D7, respectively, compared with $0.46 \pm 0.04$ in the absence of compound D7. Compound D7 did not inhibit CdsN activity suggesting that it may not be a broad spectrum inhibitor of enzymes that utilize ATP as a substrate.

To assess whether compound D7 could be used in cell culture we first exposed the compound to reducing condi-
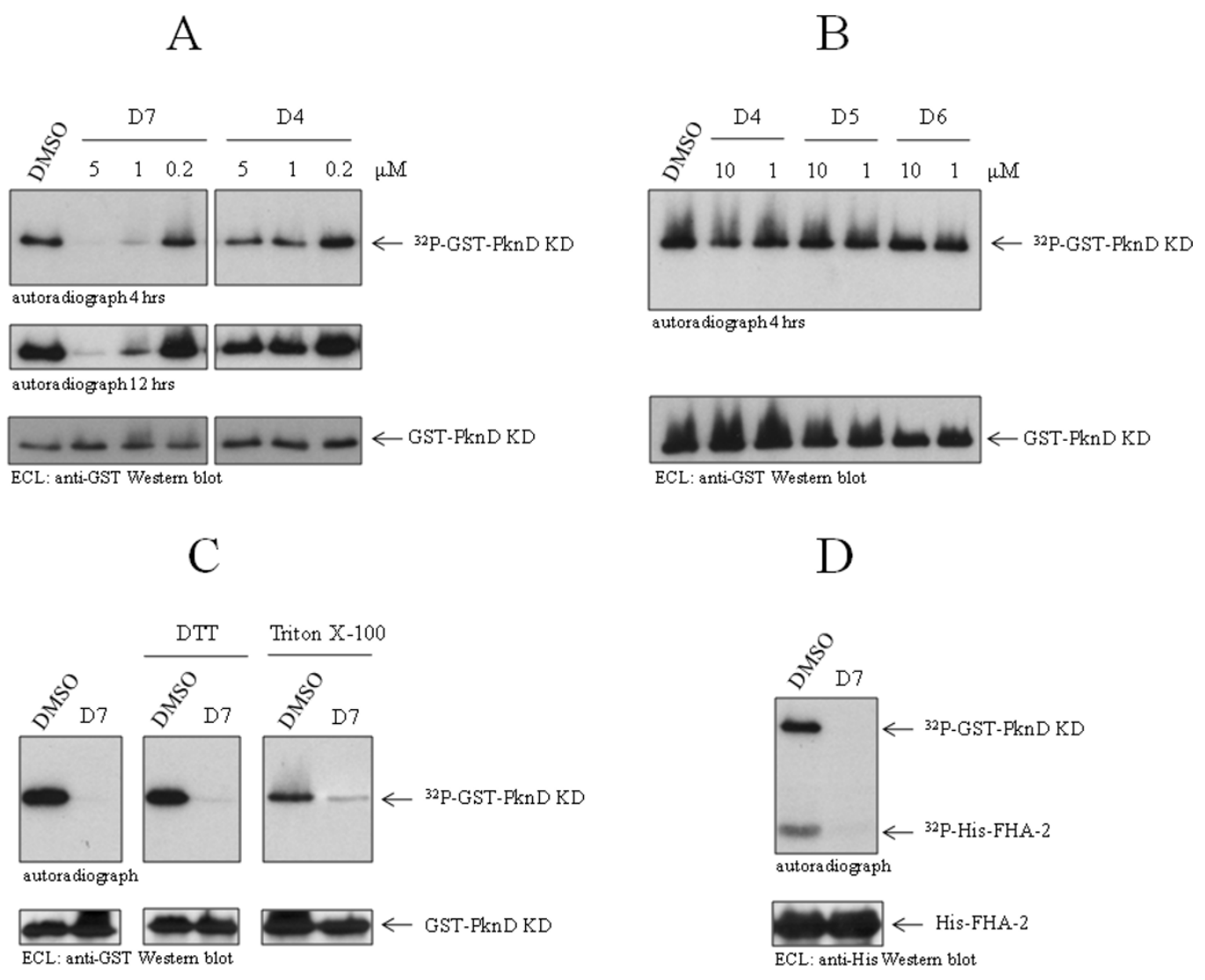

\section{Figure I}

Inhibition of PknD by compound D7. A: compound D7, but not compound D4 or DMSO, substantially inhibited PknD autophosphorylation ( ${ }^{2} \mathrm{P}-\mathrm{GST}-\mathrm{PknD} \mathrm{KD}$ ) at 5 and I $\mu \mathrm{M}$, as seen by autoradiography. B: related compounds D5 and D6 did not inhibit PknD at I or $10 \mu \mathrm{M}$. C: I mM DTT and I\% Triton X-100 did not decrease inhibition of PknD by compound D7 (used at $10 \mu \mathrm{M}$ in all panels). DMSO $(0.1 \%)$ is shown as control. D: compound D7 inhibited phosphorylation of the FHA-2 domain (32PHis-FHA-2) of CdsD by PknD. Western blotting showed equivalent amounts of protein in each autoradiograph (lower panels). 
tions similar to that found in eukaryotic cells, then tested its ability to inhibit PknD. Equivalent volumes of compound D7 $(100 \mu \mathrm{M})$ and DTT $(2 \mathrm{mM})$ were mixed on ice for 15 minutes prior to testing in the kinase assay. Compound D7 retained the ability to inhibit PknD autophosphorylation (fig. 1C) after exposure to DTT, suggesting that it would not have decreased effectiveness under the reducing conditions of the cell cytoplasm. To rule out the possibility that the inhibitory effect of D7 was due to aggregates of the compound, we tested for inhibitory activity in the presence of $1 \%$ Triton $\mathrm{X}-100$ to reduce potential aggregates. Compound D7 retained efficacy toward PknD in the presence of 1\% Triton X-100 (fig. 1C), indicating that the inhibition was not due to a non-specific effect of compound D7 aggregates.

We recently identified CdsD, an ortholog of Yersinia YscD, as a substrate of PknD and showed that PknD phosphorylated 2 FHA domains of CdsD [45]. We therefore exam- ined whether compound D7 could block phosphorylation of CdsD by PknD. Compound D7 completely blocked the phosphorylation of the CdsD FHA-2 domain by PknD (fig. 1D) indicating that, in addition to inhibiting PknD autophosphorylation, it also inhibits phosphorylation of CdsD.

\section{Effect of compound D7 on the growth of C. pneumoniae in HeLa cells}

The identification of a PknD inhibitor provides a new tool to study the role of PknD in the developmental cycle of $C$. pneumoniae. Since PknD may play a role at various times throughout the 72 hour developmental cycle we tested the effect of several compounds including compound D7 on the growth of $C$. pneumoniae in cell culture. Compounds were added to the cell culture media $1 \mathrm{hr}$ prior to infection with $C$. pneumoniae and inclusions were visualized by immunofluorescent (IF) staining at $72 \mathrm{hr}$. Compound D7 retarded the growth of C. pneumoniae in HeLa cells (fig. 2)
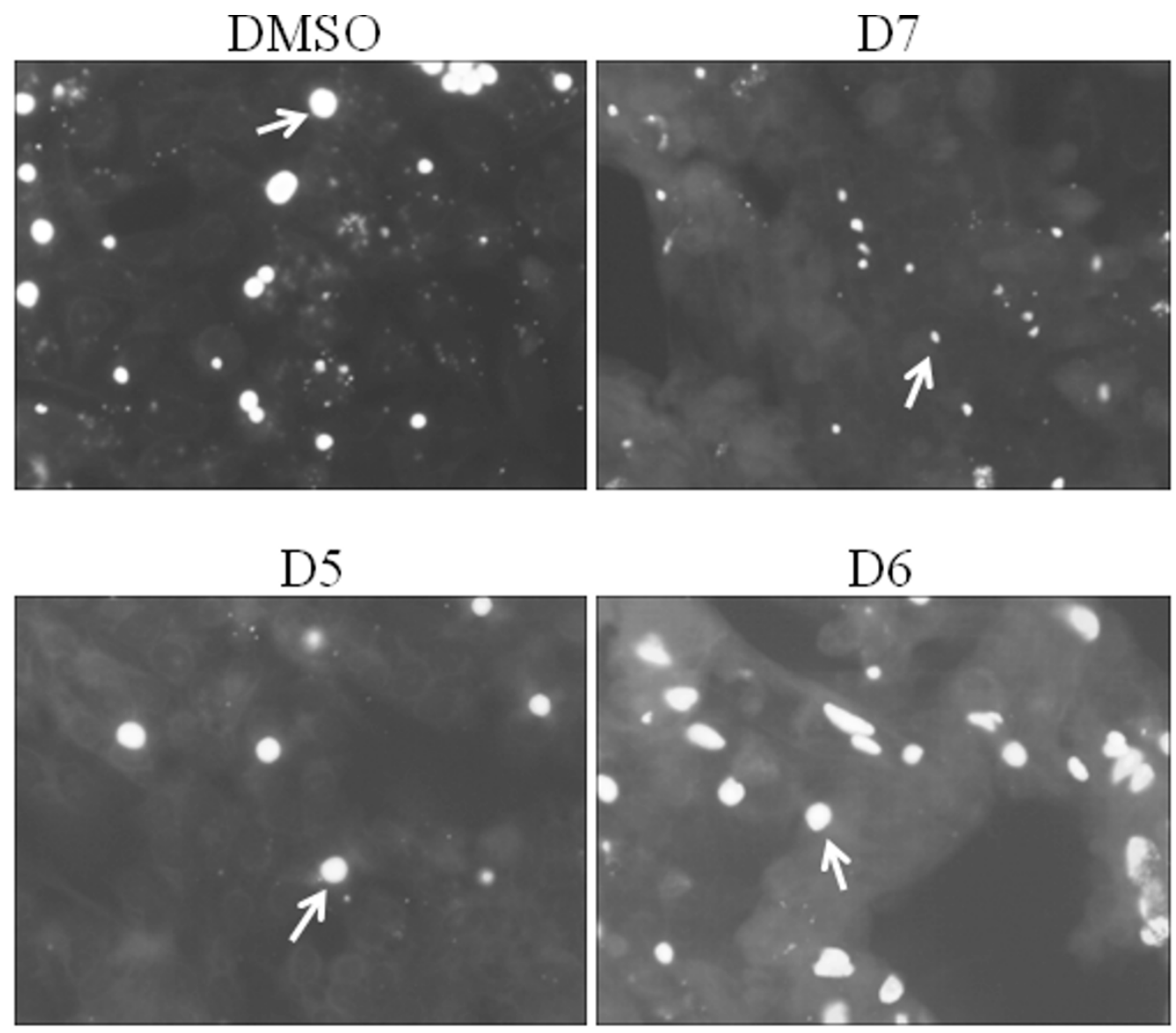

\section{Figure 2}

Compound D7 inhibits the growth of C. pneumoniae in HeLa cells. Detection of inclusions at 72 hpi by IF microscopy revealed very small inclusions when $C$. pneumoniae-infected HeLa cells were exposed to $10 \mu M$ of compound D7, but not when exposed to DMSO (0.1\%) or $10 \mu \mathrm{M}$ of compounds D5 or D6. Arrows indicate representative inclusions. Inclusions were stained with FITC-conjugated anti-LPS monoclonal antibody containing Evan's Blue counterstain. 
as indicated by the presence of very small inclusions at 72 h. Compounds D5, D6 and vehicle (0.1\% DMSO) did not have any effect on the development of inclusions judged by the presence of normal size inclusions. Given that compounds D5, D6 and D7 are JAK3 kinase inhibitors, and only compound D7 affects growth of C. pneumoniae, JAK3 inhibition is not likely responsible for the decreased chlamydial growth rate.

\section{Compound D7 exhibits a dose-dependent but time- independent effect on $\mathbf{C}$. pneumoniae growth}

To determine whether the effect of compound D7 on chlamydial growth is dose-dependent we added compound D7 to infected HeLa cells at $1 \mathrm{hr}$ post infection at final concentrations of $0.4,2$ and $10 \mu \mathrm{M}$ and assessed inclusion size at $72 \mathrm{hpi}$. Vehicle or $0.4 \mu \mathrm{M}$ of D7 resulted in normal size inclusions at $72 \mathrm{hr}$ (fig. 3A). Compound D7 at $2 \mu \mathrm{M}$ resulted in slightly smaller inclusions relative to DMSO-only exposure while D7 at $10 \mu \mathrm{M}$ resulted in very small inclusions (fig. 3A). To determine if compound D7 exerts a time-dependent effect on Chlamydia growth, the compound was added to infected cells at 15 and 24 hours post infection in addition to $1 \mathrm{hpi}$. Under each condition inclusions were very small at $72 \mathrm{hpi}$ compared to inclusions in cells exposed to vehicle (fig. 3B) indicating that the effect of compound D7 on Chlamydia growth is not restricted to a time prior to $24 \mathrm{hpi}$. These results demonstrate that compound D7 exerts a dose-dependent but time-independent effect on C. pneumoniae growth in HeLa cells.
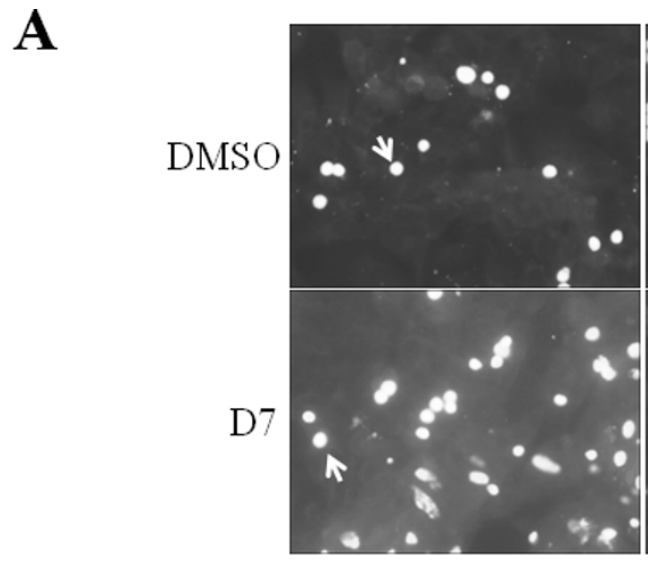

0.4

B

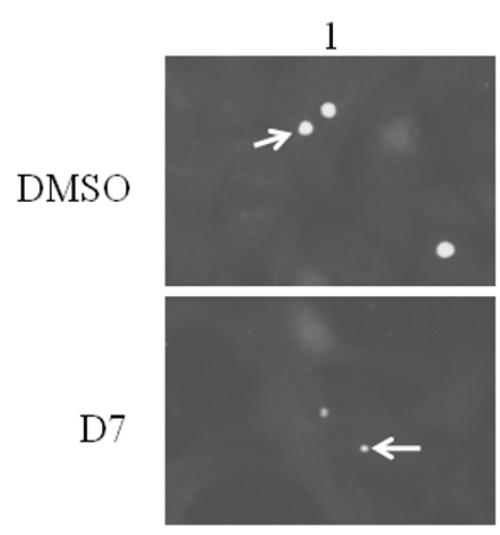

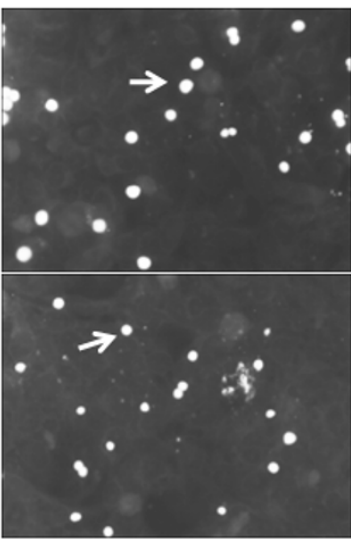

2
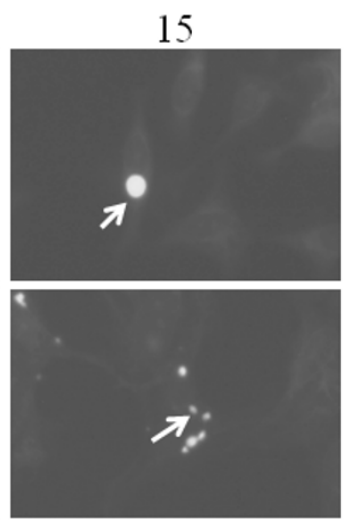

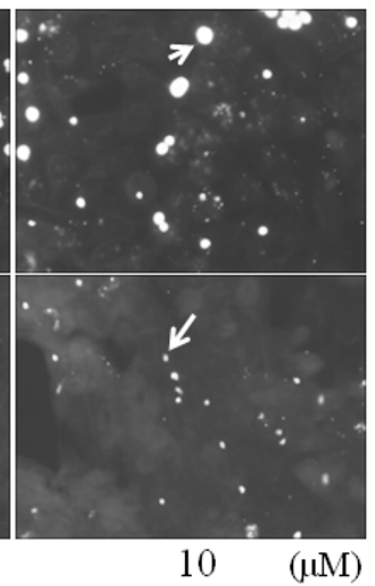

24 (HPI)
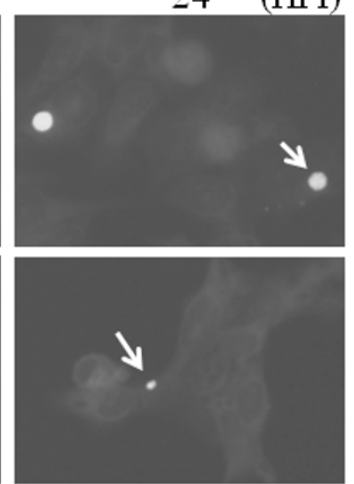

\section{Figure 3}

C. pneumoniae growth inhibition by compound D7 is dose-dependent. A: compound D7 at $0.4 \mu M$ exhibited no inhibition of chlamydial growth (normal size inclusions), $2 \mu \mathrm{M}$ exhibited partial inhibition (smaller inclusions), and I0 $\mu \mathrm{M}$ had a significant inhibitory effect (significantly reduced inclusion size) (bottom panels, left to right, respectively). DMSO controls at $0.004,0.02$, and $0.1 \%$ (top panels, left to right, respectively) did not restrict growth as indicated by inclusion size. Arrows indicate representative inclusions. B: Addition of $10 \mu \mathrm{M}$ compound D7 to C. pneumoniae-infected HeLa cells at I, I5 or 24 hpi resulted in small inclusions at $72 \mathrm{hpi}$. Inclusions were stained with FITC-conjugated anti-LPS monoclonal antibody containing Evan's Blue counterstain. 


\section{Compound D7 does not affect HeLa cell viability}

Since inhibition of $C$. pneumoniae growth could be due to an effect of compound D7 on host cell viability, we assessed whether D7 affects HeLa cell replication and cytotoxicity. Uninfected HeLa cells were incubated in the presence of $10 \mu \mathrm{M}$ compound D7 or DMSO, and cell density was assessed at 0, 22, 44 and 66 hours using a spectrophotometric assay. Compound D7 had little or no effect on HeLa cell growth rate compared to DMSO (fig. 4A). We also examined cell cytotoxicity at these times using an adenylate kinase release assay. Compound D7 exhibited the same level of cytotoxicity as DMSO at 0, 22 and 44 hours, and only slightly higher cytotoxicity levels at $66 \mathrm{hr}$ compared to DMSO-exposed cells (fig. 4B). Therefore compound D7 had little or no effect on HeLa cell viability and the inhibitory effect of D7 on chlamydial growth is not likely due to a non-specific cytotoxic effect on the host cell.

\section{Compound D7 does not block activation of the MEKIERK pathway}

It has been shown previously that activation of the MEK/ ERK pathway is necessary for chlamydial invasion of host cells [43] and sustained activation of this pathway is required for acquisition of host glycerophospholipids by Chlamydia [48]. To rule out the possibility that the inhibitory effect of compound D7 on C. pneumoniae growth could be due to an inhibition of the MEK/ERK pathway

A

HeLa cell replication

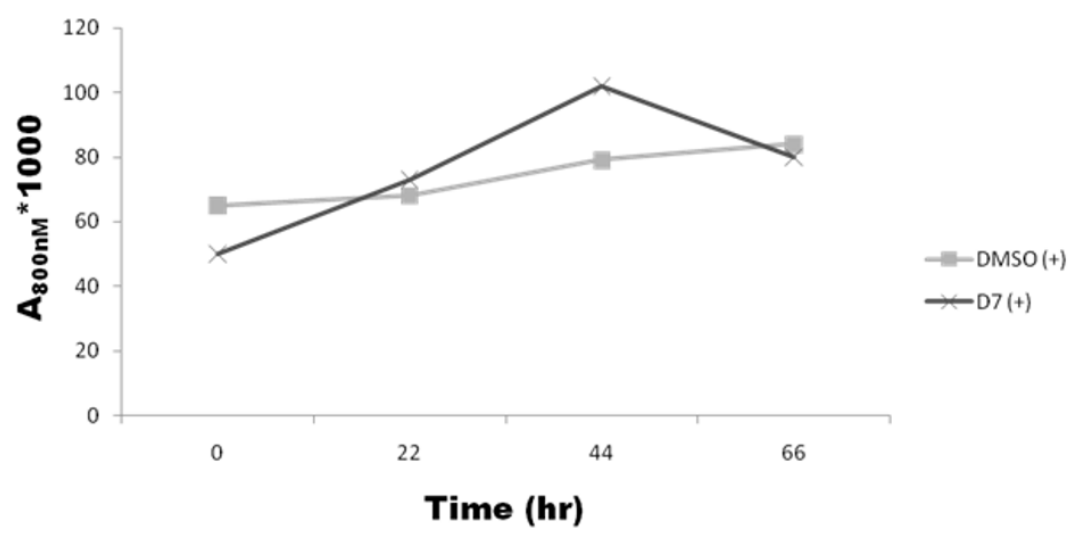

$\mathrm{B}$

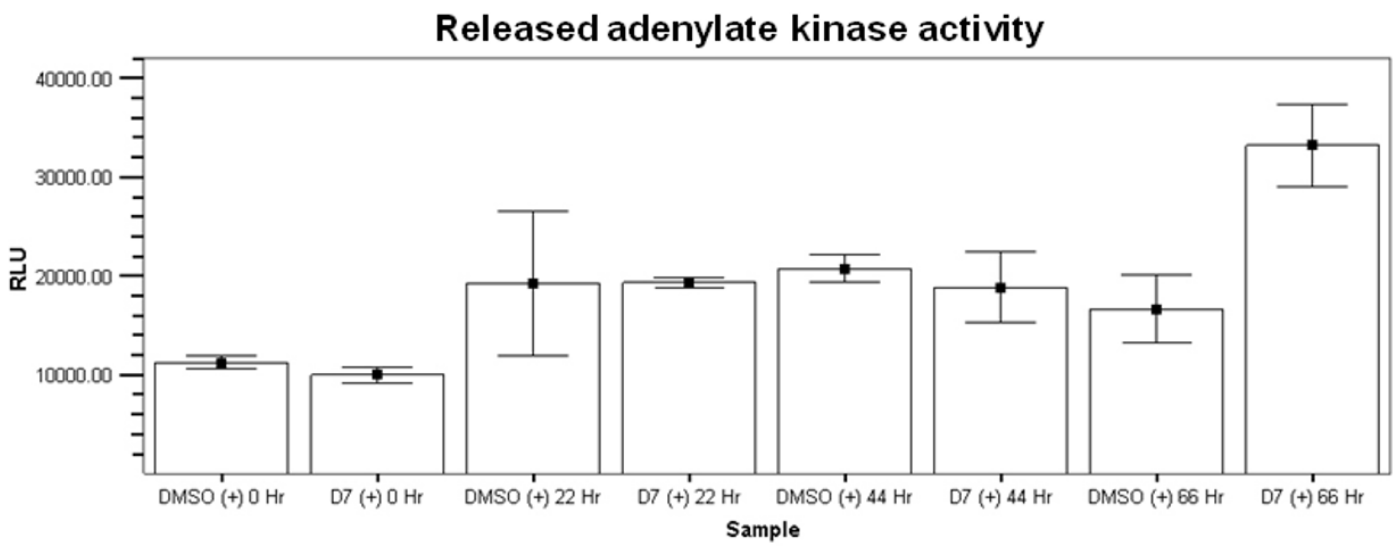

\section{Figure 4}

Compound D7 does not reduce HeLa cell viability. A: subconfluent HeLa cell monolayers incubated in MEM containing either DMSO $(0.1 \%)$ or compound D7 $(10 \mu \mathrm{M})$ with $2 \mu \mathrm{g} / \mathrm{mL}$ cycloheximide $(+)$, were collected by trypsinization and the cell density was measured by absorbance at $800 \mathrm{nM}$ at the times indicated. Compound D7 did not significantly alter HeLa cell number compared to DMSO alone. B: cell culture supernatant adenylate kinase activity from the samples in (A). Exposure of HeLa cells to $10 \mu \mathrm{M}$ compound D7 for 44 hours was not more cytotoxic than cells exposed to DMSO. At 66 hours there was a small increase in HeLa cell release of adenylate kinase in the D7-exposed group. Error bars represent means plus 2 standard deviations. 
we assessed the level of ERK1 and ERK2 (p44/p42 MAP kinase, respectively) phosphorylation in the presence of compound D7. HeLa cells exposed to either 10 or $100 \mu \mathrm{M}$ of compound D7 contained high levels of phosphorylated p44 and p42 MAP kinase following EGF stimulation. HeLa cells exposed to 10 or $25 \mu \mathrm{M}$ U0126, a specific inhibitor of MEK1/2, were used as control and did not contain phosphorylated p44 or p42 MAP kinase following EGF stimulation (fig. 5). This result demonstrates that compound D7 does not block phosphorylation of p44/ p42 MAP kinase in HeLa cells, suggesting that chlamydial growth inhibition caused by D7 was not due to a non-specific blockage of the MEK/ERK pathway.

\section{Effect of compound D7 on the growth of Salmonella} enterica sv. Typhimurium and $C$. trachomatis serovar $D$ Since compound D7 could inhibit C. pneumoniae growth indirectly by affecting a common signaling pathway of the host cell, we examined the effect of compound D7 on the growth of another intracellular bacterial pathogen, Salmonella enterica sv. Typhimurium SL1344. Compound D7, as well as compounds D4, D5, D6 and DMSO, did not inhibit Salmonella replication in HeLa cells (fig. 6A), suggesting that the inhibitory effect of D7 was specific to $C$. pneumoniae and not the result of interference with a common signaling pathway of the host cell related to intracellular pathogens. To determine whether compound D7 was inhibiting a host signaling pathway or cellular function used by the chlamydiae spp. we examined the growth of Chlamydia trachomatis serovar D in HeLa cells in the presence of compound D7. Compound D7 did not inhibit the growth of C. trachomatis in HeLa cells as assessed by IF staining of mature inclusions present at 48 $\mathrm{hr}$ (fig. 6B), indicating that compound D7 is specific for $C$. pneumoniae, does not inhibit $C$. trachomatis, and does not block a common signaling pathway used by chlamydiae spp.

\section{Compound D7 does not cause chlamydial persistence and does not block differentiation or replication}

Since the evidence indicates the inhibitory effect of compound D7 on Chlamydia growth can be exerted early in the developmental cycle (between 1-24 hpi), it is possible that the inhibitory effect occurs at a specific stage viz. EB to $\mathrm{RB}$ differentiation or $\mathrm{RB}$ replication. Alternatively, a block in replication could be due to the induction of persistence which occurs under conditions of limiting tryptophan or iron. To determine whether compound D7 blocks chlamydial growth at a specific stage, we used electron microscopy to look for various developmental forms. Figs. 7A and 7B show representative inclusions at $48 \mathrm{hpi}$ from C. pneumoniae-infected HeLa cells incubated in the presence of $10 \mu \mathrm{M}$ compound D7. These inclusions are smaller and contain fewer bacteria compared with chlamydial inclusions in the absence of compound D7 (figs. 7C and 7D), consistent with results seen using IF staining. All three developmental forms of Chlamydia, (EB, IB and $\mathrm{RB}$ ) were seen in the presence of compound D7, and no aberrant forms or PB were detected, indicating that the inhibition of chlamydial growth was not due to the induction of persistent bodies. These results show that
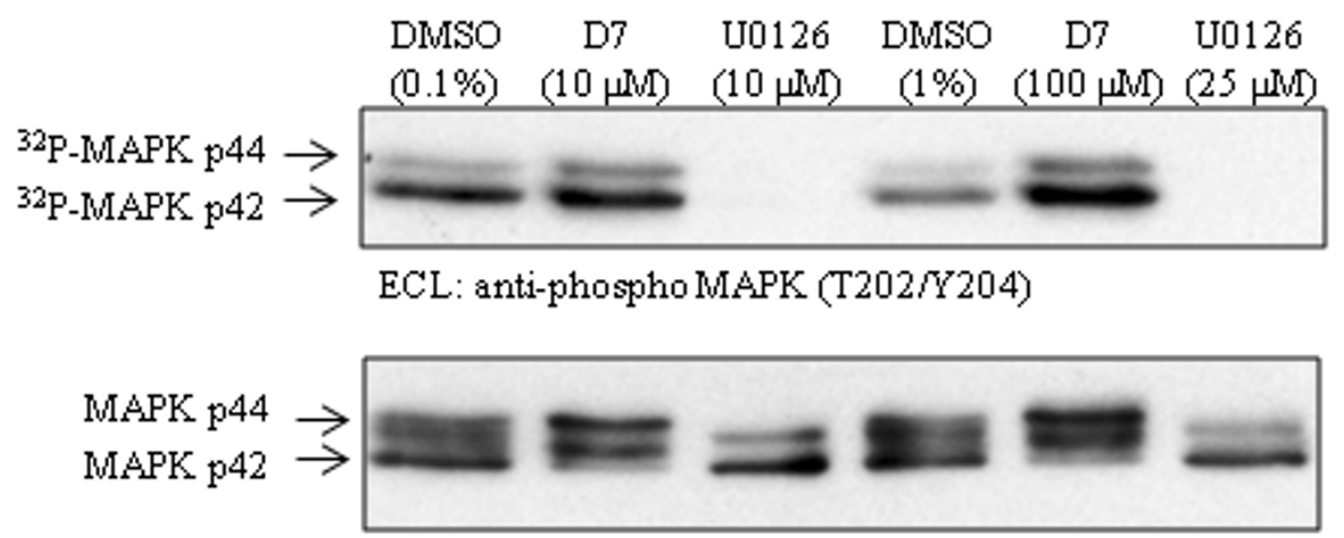

ECL: anti-MAPK Western blot

\section{Figure 5}

Compound D7 does not block activation of the MEK/ERK pathway in EGF-stimulated HeLa cells. HeLa cells incubated with DMSO, compound D7 or U0I26 were activated with EGF and the levels of MAP kinase phosphorylation were determined by Western blot using anti-phospho ERKI/2 antibody. Compound D7 at I0 and I00 $\mu$ M, and DMSO at 0.1 and I\%, did not prevent phosphorylation of MAP kinase following EGF stimulation of HeLa cells. U0I26 at 10 and $25 \mu$ M completely prevented phosphorylation of MAP kinase. Blots were probed with antibody to phosphorylated MAPK (upper panel), and with antibody to total MAPK (lower panel). 
A

\section{SL1344 Intracellular replication}

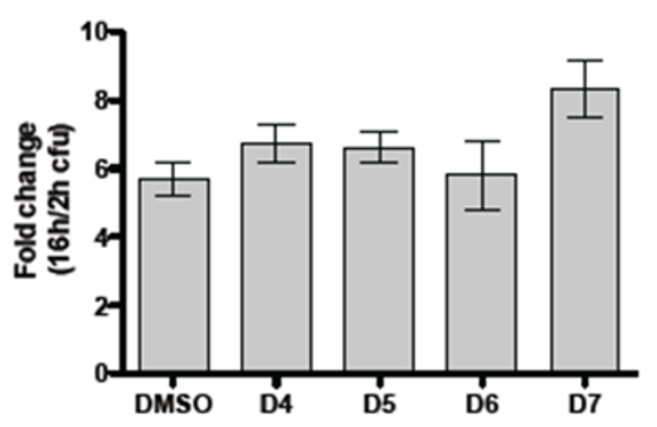

B

C.pneumoniae CWL029 C. trachomatis serovar D

(72 HPI)

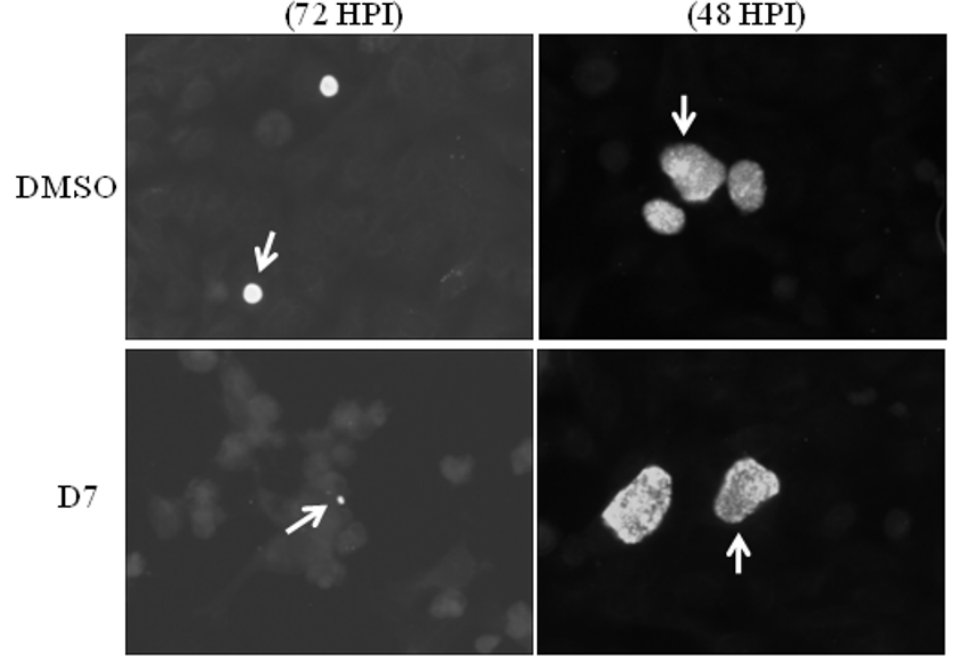

\section{Figure 6}

Compound D7 does not inhibit the growth of Salmonella enterica sv. Typhimurium or $C$. trachomatis serovar D in HeLa cells. A: compounds D4, D5, D6 and D7 (I0 $\mathrm{M})$ or DMSO $(0.1 \%)$, did not prevent replication of Salmonella enterica sv. Typhimurium SLI 344 in HeLa cells. Compounds were added to the media 2 hours after host cell infection, and bacteria harvested at both 2 and 16 hpi in order to plot the fold change in colony forming units. B: compound D7 did not inhibit the growth of Chlamydia trachomatis serovar D. Compound D7 (10 $\mu \mathrm{M})$ was added to cell monolayers I hpi and inclusions were stained at $48 \mathrm{hpi}$. Large inclusions were seen in both D7- (bottom right panel) and DMSO-exposed (0.1\%; top right panel) cells while small inclusions were seen for $C$. pneumoniae in D7-exposed cells. Arrows indicate representative inclusions. The monoclonal antibody contained Evan's Blue counterstain for detection of host cells.

compound D7 attenuates Chlamydia growth by decreasing the number of bacteria present in infected cells.

\section{Compound D7 decreases the number and infectivity of C.} pneumoniae progeny

To determine whether Chlamydia progeny are infectious after exposure to compound D7, a blind passage experiment was performed. C. pneumoniae-infected HeLa cells were incubated in the presence of compound D7 or DMSO and the cells were lysed at 72 or $84 \mathrm{hr}$. Lysates containing chlamydiae were either undiluted, or diluted in media lacking compound D7 and blind passaged onto fresh HeLa cell monolayers. Compound D7 reduced the number of infectious chlamydiae compared with DMSO alone at both times by greater than $90 \%$ based on inclusion counts (fig. 8). In addition to reducing the number of inclusions, compound D7-exposed C. pneumoniae produced inclusions that were smaller in size compared to unexposed cultures, consistent with results seen on first passage (figs. 2, 3). These results indicate that compound D7 decreases the number and infectivity of $C$. pneumoniae progeny.

\section{Discussion}

Chlamydiae are obligate intracellular pathogens that have a unique biphasic developmental cycle. We have previ- ously shown that C. pneumoniae contains three Ser/Thr protein kinases and that one of these, $\mathrm{PknD}$, is a membrane-associated kinase that phosphorylates CdsD, a structural protein of the type III secretion system [45]. In the present study we have identified a selective inhibitor of PknD and show that this compound blocks phosphorylation of $\mathrm{CdsD}$ in vitro, retards the intracellular growth rate and decreases the number of infectious C. pneumoniae produced following infection of HeLa cells.

To elucidate the role of PknD in the chlamydial developmental cycle, we screened a small library of known eukaryotic kinase inhibitors in an attempt to identify a PknD inhibitor. In this study we show that compound D7 is a potent inhibitor of C. pneumoniae PknD activity in vitro. PknD autophosphorylation and subsequent phosphorylation of the substrate CdsD were completely inhibited by compound D7. When added to C. pneumoniaeinfected HeLa cells, the 3' pyridyl oxindole compound retarded chlamydial replication. The restriction of the developmental cycle was not due to the induction of chlamydial persistence as seen with interferon- $\gamma$ or iron deprivation $[34,38]$ since PB were not detected in inclusions when viewed by electron microscopy. Compound D7 also decreased the number of infectious $C$. pneumoniae 


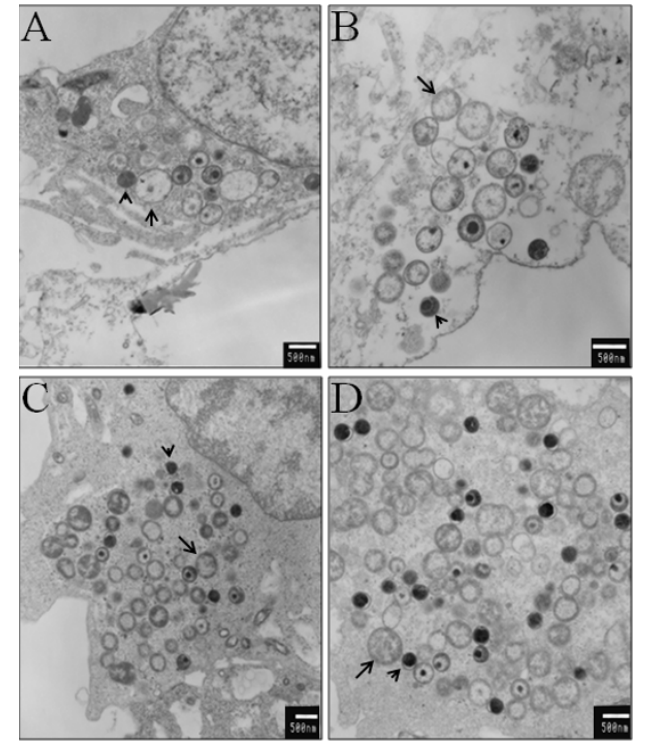

Figure 7

Normal developmental forms of $C$. pneumoniae are found within compound D7-exposed inclusions. At 48 hpi, infected HeLa cells incubated in MEM containing $10 \mu \mathrm{M}$ of either compound D6 or D7 were observed by TEM. A, B: inclusions in D7-exposed cells are smaller and contain fewer bacteria, but all three developmental forms (EB, IB and RB) of $C$. pneumoniae are present. C, D: $C$. pneumoniae inclusions exposed to compound D6 are normal in size and contain the same normal developmental forms. Size bars are indicated in white $(500 \mathrm{~nm})$. Representative micrographs indicating RB (arrows) and EB (arrow heads) are shown.

upon passage suggesting that the compound interferes with an essential step in C. pneumoniae development.

The mechanism of chlamydial growth retardation by compound D7 is unknown but an involvement of host cell JAK3 is unlikely because the expression of JAK3 is restricted to the hematopoietic cell lineage [49-51] and HeLa cells do not express JAK3. The absence of JAK3 in Chlamydia-infected HeLa cells is supported by a recent study that failed to detect the induction or expression of the JAK3 substrate, STAT5, in C. trachomatis-infected HeLa cells [52]. In addition, other potent JAK3 inhibitors (compounds D4, D5 and D6) did not interfere with C. pneumoniae growth in HeLa cells. Therefore the mechanism of $C$. pneumoniae growth retardation in HeLa cells is unlikely due to an effect of compound D7 on JAK3 activity.

Our data also rule out an effect of compound D7 on the MEK/ERK signaling pathway required for chlamydial infection and intracellular growth. Activation of the MEK/ ERK pathway has been shown to be essential for chlamydial invasion of HeLa cells [43], and sustained activation of Raf-MEK-ERK-cPLA2 is also required for acquisition of

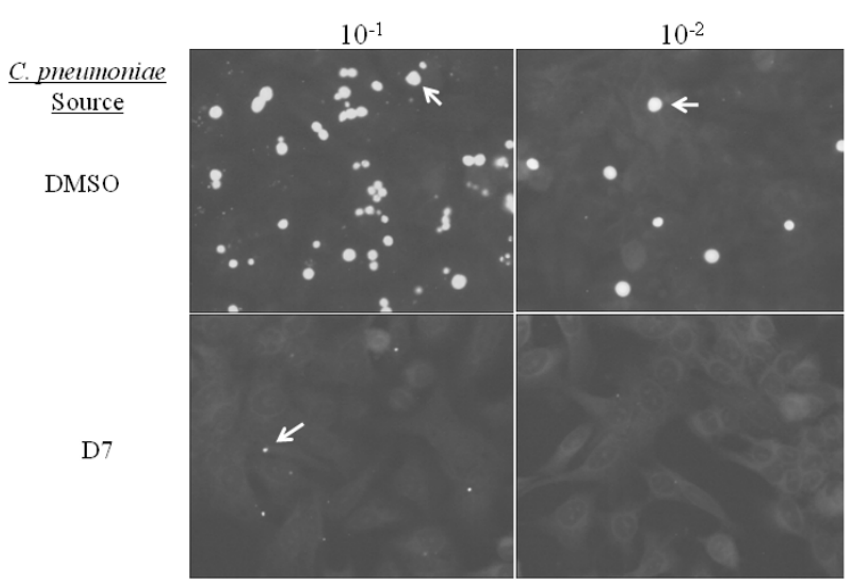

\section{Figure 8}

Compound D7 reduces the number and infectivity of C. pneumoniae progeny. HeLa cells were infected with $C$. pneumoniae (MOI of 5) and MEM containing either DMSO $(0.1 \%)$ or D7 (I0 $\mu \mathrm{M})$ was added at I hpi. Cells were lysed at $72 \mathrm{hpi}$ and chlamydial lysates diluted $10^{-1}$ and $10^{-2}$ and used to infect fresh HeLa cell monolayers. Infected cells were then incubated for 72 hours in MEM (without D7 or DMSO) and inclusions were stained with FITC-conjugated anti-LPS monoclonal antibody. C. pneumoniae harvested from DMSOexposed HeLa cells produced many inclusions of normal size upon subsequent passage (top panels; dilution of passage indicated). A substantial reduction in both the number and size of inclusions was seen with chlamydiae harvested from HeLa cells exposed to compound D7 (bottom panels). Similar results were obtained with undiluted chlamydial lysates and with lysates harvested at 84 hpi (data not shown).

glycerophospholipids and growth by C. pneumoniae [48]. In our experiments $100 \mu \mathrm{M}$ of compound D7 (10 fold higher than the concentration that inhibits chlamydial replication) did not interfere with MAP kinase phosphorylation in response to EGF, indicating that compound D7 does not block activation of the MEK/ERK pathway and that interference with this signaling pathway is not the mechanism of compound D7-mediated growth retardation.

Since protein kinase inhibitors are known to be promiscuous [53-55] and compound D7 could inhibit a kinase or other enzyme required for the growth of C. pneumoniae, a similar growth inhibition by compound D7 might be expected for other intracellular bacteria. Since compound D7 did not inhibit the growth of Chlamydia trachomatis serovar D or Salmonella enterica sv. Typhimurium SL1344, an effect of D7 on a common signaling pathway used by intracellular pathogens is not likely the mechanism of $C$. pneumoniae growth retardation.

Our results show that compound D7 inhibits the autophosphorylation of PknD and subsequent phosphoryla- 
tion of C. pneumoniae CdsD in vitro and significantly retards the growth of $C$. pneumoniae in HeLa cells. However, our data does not allow us to state unequivocally that the reduced rate of growth in the presence of compound D7 is directly due to inhibition of PknD activity. Our attempts to detect phosphorylated CdsD in vivo by mass spectrometry have not been successful as it is technically difficult to harvest enough CdsD protein suitable for this method. We are exploring other methods for detecting $\mathrm{CdsD}$ phosphorylation in vivo as the detection of the phosphorylation status of PknD or CdsD in the presence of compound D7 would allow us to make a stronger link between PknD activity and growth rate. Since C. trachomatis contains a PknD ortholog we might expect compound D7 to affect $C$. trachomatis but this is not the case as compound D7 did not affect the growth of $C$. trachomatis in HeLa cells. However, the limited homology between the catalytic domains of the PknD orthologs in C. trachomatis and C. pneumoniae might explain the differential effect of compound D7 on their respective growth rates. We are presently initiating experiments to assess whether compound D7 has any inhibitory effect on PknD orthologs of other chlamydial species and to determine effects on bacterial replication rates.

Electron microscopic examination of Chlamydia-infected cells exposed to compound D7 revealed the presence of very small inclusions with significantly reduced numbers of bacteria. Inclusions contained all 3 developmental forms including RB, EB and IB and therefore both replication and differentiation of $C$. pneumoniae occurred in the presence of D7, albeit at a reduced rate. If inhibition of PknD is the mechanism by which compound D7 exerts its inhibitory effect on chlamydial replication, the presence of replicating RB in inclusions indicates that PknD activity is not essential for bacterial replication. In this scenario one could envisage a redundant or compensatory signaling pathway that circumvents the effect of compound D7mediated PknD inhibition. Alternatively, PknD may be involved in a signaling pathway indirectly related to replication and that when inhibited only slows the rate of replication. It is also possible that PknD is an essential enzyme required for replication, but is only partially inhibited in cell culture by the concentration of compound D7 used in our growth experiments. Indeed, it is known that chlamydial isolates can be heterogeneous in nature and therefore a subpopulation of Chlamydia may have been partially resistant to the effects of compound D7. Nonetheless, C. pneumoniae grown in the presence of compound D7 and subsequently passaged onto fresh HeLa cell monolayers failed to propagate and develop inclusions suggesting PknD may also be involved in the production of infectious bacteria. Inhibition of $\mathrm{PknD}$ could manifest as multiple biological effects if there is more than one PknD substrate, or if the affected biological events are linked. More work is needed to elucidate the role of PknD and the exact mechanism by which com- pound D7 inhibits the growth and development of $C$. pneumoniae. These experiments, however, will be difficult to conduct in the absence of a genetic transformation system for chlamydiae.

\section{Conclusion}

We have identified a novel inhibitor of $C$. pneumoniae growth and development, and its biological effects may be mediated via inhibition of PknD. It is tempting to speculate that PknD plays an essential role in the developmental cycle of $C$. pneumoniae, which may include a role in replication and/or in the production of infectious progeny, but this hypothesis cannot be directly tested in the absence of a PknD knockout. The approach of using novel chemicals in cell culture to inhibit other Ser/Thr protein kinases of chlamydiae viz. Pkn1 or Pkn5 may prove fruitful in elucidating their roles in chlamydial development.

\section{Methods \\ Reagents and Cell Lines}

Minimal essential medium (MEM) (Invitrogen, Burlington) containing Earle's salts and L-glutamine was supplemented with $10 \%$ fetal bovine serum. The Calbiochem InhibitorSelect Protein Kinase Inhibitor Library I containing 80 receptor tyrosine kinase inhibitors and atypical kinase inhibitors was from EMD (San Diego). MP Biomedicals (Santa Ana) supplied radiolabelled ATP $\left(\left[\gamma-{ }^{32} \mathrm{P}\right]-\right.$ ATP) for the in vitro kinase assays. HeLa 229 cells were obtained from ATCC (Manassas). Chlamydophila pneumoniae CWL029 and Chlamydia trachomatis serovar D were obtained from ATCC (cat. \#VR1310 and \#VR885, respectively). E. coli Rosetta pLysS and BL21(DE3) pLysS were from Novagen (EMD). Epidermal growth factor (EGF) and the MEK inhibitor U0126 were from Sigma (Oakville). U0126 was resuspended in DMSO immediately prior to addition to cell culture in the MEK/ERK activation experiment.

\section{Protein Expression and Purification}

GST-PknD KD and His-FHA-2 were prepared as described [45]. Key parameters for preparing active kinase domain included cooling the E. coli cultures to $20^{\circ} \mathrm{C}$ prior to induction, inducing with $0.2 \mathrm{mM}$ IPTG, and harvesting cells after 2 hours of recombinant protein expression at room temperature.

\section{Protein Kinase Activity}

Eighty cell permeable and ATP competitive protein kinase inhibitors were purchased from EMD (San Diego). Each compound in the InhibitorSelect protein kinase library was screened at $10 \mu \mathrm{M}$ (unless otherwise noted) in an in vitro PknD autophosphorylation assay. Briefly, each reaction contained 100 ng GST-PknD KD, $20 \mu \mathrm{M}$ ATP, 5 mM $\mathrm{MnCl}_{2}$ and $3 \mu \mathrm{Ci}\left[\gamma_{-32} 32 \mathrm{P}\right]$-ATP in $25 \mathrm{mM}$ HEPES buffer $(\mathrm{pH}$ 7.1) supplemented with $1 \times$ complete EDTA-free protease inhibitors, unless otherwise noted. Reactions were incubated for $90 \mathrm{~min}$. at $33^{\circ} \mathrm{C}$, terminated with SDS-PAGE 
loading buffer, separated by 10\% SDS-PAGE and transferred to polyvinyldinedifluoride (PVDF) membrane. Membranes were exposed to Kodak X-OMAT film for 1-12 hours at $-80^{\circ} \mathrm{C}$ and subsequently developed using an $\mathrm{X}$ ray processor.

\section{ATPase Activity}

ATP hydrolysis by GST-CdsN purified from glutathioneagarose beads was measured using a malachite green assay (R \& D Systems). Reaction mixtures contained $100 \mathrm{ng}$ of GST-CdsN, $4 \mathrm{mM}$ ATP, $50 \mathrm{mM}$ Tris-HCL pH 7.0, $5 \mathrm{mM}$ $\mathrm{MgCl}_{2}$, and $10 \mathrm{mM} \mathrm{KCl}$. Compound D7 was added to final concentrations of $1 \mu \mathrm{M}, 5 \mu \mathrm{M}, 10 \mu \mathrm{M}$ and $100 \mu \mathrm{M}$. The reaction mixture $(50 \mu \mathrm{L})$ was incubated at $37^{\circ} \mathrm{C}$ for $30 \mathrm{~min}$. The reaction was stopped by the addition of $10 \mu \mathrm{L}$ of Malachite Green Reagent A followed by $10 \mu \mathrm{L}$ of Malachite Green Reagent $B$ and incubated at room temperature for one minute before an $\mathrm{OD}_{610}$ reading was taken, according to the manufacturer's instructions.

\section{Immunofluorescent Microscopy and Chlamydia Growth Experiments}

HeLa cells $\left(1 \times 10^{5}\right)$ on coverslips in shell vials were infected with C. pneumoniae CWL029 (MOI of 1) using centrifugation, and replacement media containing $2 \mu \mathrm{g} /$ $\mathrm{mL}$ cycloheximide was added at $1 \mathrm{hpi}$. Protein kinase inhibitors (compounds D4, D5, D6 and D7) were added to the replacement media to a final concentration of 10 $\mu \mathrm{M}$ (unless otherwise noted), for the duration of the Chlamydia developmental cycle (72 hours). For time course immunofluorescence (IF) experiments, compound D7 was added at 1, 15 and 24 hpi. For IF staining cell monolayers were fixed in methanol for 10 minutes at 72 hpi for C. pneumoniae and at 48 hpi for C. trachomatis. Inclusions were stained with the Pathfinder reagent, a FITC-conjugated anti-LPS monoclonal antibody (BioRad, Mississauga) containing Evan's Blue counterstain. Images were captured at $400 \times$ magnification using an Olympus BX51 fluorescent microscope equipped with a color camera ( $\mathrm{Q}$ color 5; Olympus). To determine the infectivity of Chlamydia grown in the presence of inhibitors, HeLa cells were infected with C. pneumoniae CWL029 and grown for 72 or $84 \mathrm{hrs}$ in the presence of various compounds (used at $10 \mu \mathrm{M}$ ) or vehicle (DMSO $0.1 \%$ ) then cells were lysed with glass beads into fresh MEM. Serial dilutions of lysates were used to infect fresh HeLa cells and inclusions were stained at $72 \mathrm{hr}$ as described above.

\section{Salmonella Infection Assay}

The effect of compound D7 on the growth of Salmonella enterica sv. Typhimurium SL1344 [56] in HeLa cells was determined using a cell invasion assay. Briefly, overnight bacterial cultures grown in Luria-Bertani broth (LB) were pelleted, resuspended in $1 \mathrm{~mL}$ PBS and diluted in DMEM containing $10 \%$ FBS to an MOI of $\sim 1: 100$. An aliquot (0.5
$\mathrm{mL}$ ) of the bacterial suspension was added to HeLa cells in a 24 -well plate and incubated at $37^{\circ} \mathrm{C}$ in a $5 \% \mathrm{CO}_{2}$ atmosphere for 10 minutes. The wells were then washed $3 \times$ with PBS and incubated in DMEM for an additional 20 minutes. The medium was removed and the cells were incubated in fresh DMEM containing $100 \mu \mathrm{g} / \mathrm{mL}$ gentamycin for 1.5 hours. Culture media was replaced with fresh DMEM containing $10 \mu \mathrm{g} / \mathrm{mL}$ gentamycin and either $0.1 \% \mathrm{DMSO}$, or $10 \mu \mathrm{M}$ compound D4, D5, D6 or D7. At 2 and $16 \mathrm{hpi}$, intracellular bacteria were recovered by lysing HeLa cells in PBS containing 1\% Triton X-100 and $0.1 \%$ SDS. Lysates were serially diluted, plated on LB plates, incubated overnight and colonies subsequently counted.

\section{HeLa Cell Viability}

The effect of compound D7 on HeLa cell viability was determined. Briefly, 10 or $100 \mu \mathrm{M}$ compound D7, or $0.1 \%$ DMSO, with or without cycloheximide in MEM, was added to subconfluent HeLa cells in 6-well plates. At 0, 22, 44 and 66 hours supernatants were harvested and tested for the presence of adenylyl kinase using a cytotoxicity assay (Lonza ToxiLight ${ }^{\oplus}$ BioAssay, Rockland). The cytotoxicity assay was performed as per the manufacturer's protocol. Briefly, supernatants from HeLa cell cultures incubated in the presence of compound D7 or DMSO (in MEM containing cycloheximide) were tested for evidence of eukaryotic cell cytotoxicity. Aliquots (5 uL) of each supernatant were mixed with $25 \mathrm{uL}$ of Adenylate Kinase Detection Reagent and samples were incubated at room temperature for 5 minutes. Relative light units (RLUs) were measured using a 20/20 n Single Tube Luminometer from Turner BioSystems (Sunnyvale). Assays were conducted in triplicate for each condition. Cell monolayers were washed with warm PBS. $0.75 \mathrm{~mL}$ of trypsin was added to each well, and $0.75 \mathrm{~mL}$ of MEM was added after complete trypsinization (trypsinization was monitored by light microscopy). Each sample was thoroughly resuspended and aliquoted into a plastic cuvette and the cell number immediately quantitated by determining the optical density at $800 \mathrm{nM}$ [57] using a spectrophotomer.

\section{MEKIERK Activation}

To determine whether compound D7 interferes with activation of the MEK/ERK pathway, HeLa cells were exposed to compound D7, DMSO, or the specific MEK inhibitor U0126, activated with EGF and then lysates tested by Western blot for phosphorylated and total ERK as described [43]. Briefly, subconfluent HeLa cells in 6-well plates were serum-starved for 3.5 hours prior to incubation for $45 \mathrm{~min}$. in either $0.1 \% \mathrm{DMSO}, 10$ or $100 \mu \mathrm{M} \mathrm{com}$ pound D7 or 10 or $25 \mu \mathrm{M}$ U0126 in serum-free MEM. Cells were then incubated with $100 \mathrm{ng} / \mathrm{mL}$ EGF in serumfree MEM for 2 minutes before being scraped in $0.5 \mathrm{~mL}$ ice-cold lysis buffer (50 mM HEPES pH 7.1, $150 \mathrm{mM}$ 
$\mathrm{NaCl}, 1 \mathrm{mM}$ EDTA, $1 \times$ complete EDTA-free protease inhibitors (Roche, Mississauga), $1 \times$ phosSTOP phosphatase inhibitors (Roche) and 1\% Triton X-100). An equivalent amount of protein from each sample (450 ng) was separated by $10 \%$ SDS-PAGE and transferred to PVDF membrane. The membrane was blocked for 1 hour in TBS-T containing 4\% BSA, and then incubated in 1:1000 anti-phospho-p44/42 MAPK (Thr202/Tyr204) antibody (\#9101, Cell Signaling Technology, Danvers) overnight at $4{ }^{\circ} \mathrm{C}$ in blocking buffer. The membrane was washed $3 \times$ with PBS containing $0.1 \%$ Triton X-100, incubated in 1:4000 goat anti-rabbit IgG HRP-conjugate antibody (Sigma) in blocking buffer for 1 hour at room temperature, washed and developed using enhanced chemiluminescence (ECL) reagents (Amersham, Piscataway). The PVDF membrane was then stripped of antibody, blocked, re-probed with 1:1000 anti-p44/42 MAPK antibody (\#9102, Cell Signaling Technology) and developed as above.

\section{Transmission Electron Microscopy}

HeLa cells $\left(1 \times 10^{6}\right)$ in $9 \mathrm{~cm}^{2}$ wells of six-well plates were infected with C. pneumoniae CWL029 at a multiplicity of infection of 1 . Compounds were added at $1 \mathrm{hpi}$ and cells harvested at $48 \mathrm{hpi}$. Cells were fixed overnight at $4^{\circ} \mathrm{C}$ in $0.1 \mathrm{M}$ sodium cacodylate buffer containing $2 \%$ gluteraldehyde, embedded in araldite resin and thin sections were viewed using a Jeol JEM 1200EX electron microscope at $12,000 \times$ magnification.

\section{Abbreviations}

EB: elementary body; ECL: enhanced chemiluminescence; hpi: hours post infection; IB: intermediate body; IF: immunofluorescence; LB: Luria-Burtani broth; PB: persistent body; PknD: protein kinase D; RB: reticulate body; T3SS: type III secretion system.

\section{Authors' contributions}

CBS conducted the ATPase assay and DCB conducted the HeLa cell cytotoxicity analysis and prepared the associated bar graph. BKC conducted the Salmonella growth experiment and prepared the associated bar graph. JBM contributed to study conception and design and drafting the manuscript. DLJ contributed to study conception and design, carried out all other experiments and drafted the manuscript. All authors read and approved the final manuscript.

\section{Acknowledgements}

We thank Dr. Eric Brown and Dr. Gerry Wright for helpful advice and guidance on this project. We are grateful to all members of the Mahony lab for stimulating research discussions. A special thanks to Rick McKenzie for technical help with the Jeol JEM I 200EX electron microscope. Both DLJ and CBS are recipients of a Father Sean O'Sullivan Graduate Scholarship. This work was funded in part by a grant to JBM from the Canadian Institutes of Health Research.

\section{References}

I. Hahn DL, Azenabor AA, Beatty WL, Byrne GI: Chlamydia pneumoniae as a respiratory pathogen. Front Biosci 2002, 7:e66-e76.

2. Paldanius $M$, Juvonen $R$, Leinonen $M$, Bloigu $A$, Silvennoinen-Kassinen S, Saikku P: Asthmatic persons are prone to the persistence of Chlamydia pneumoniae antibodies. Diagn Microbiol Infect Dis 2007, 59: I I7-I 22.

3. Sutherland ER, Martin RJ: Asthma and atypical bacterial infection. Chest 2007, I32:1962-1966.

4. Campbell LA, Kuo CC, Grayston JT: Chlamydia pneumoniae and cardiovascular disease. Emerg Infect Dis 1998, 4:571-579.

5. Grayston JT: Background and current knowledge of Chlamydia pneumoniae and atherosclerosis. J Infect Dis 2000, I 8 I (Suppl 3):S402-S4I0.

6. Grayston JT: Chlamydia pneumoniae and atherosclerosis. Clin Infect Dis 2005, 40: I I31-I I 32.

7. Ardeniz O, Gulbahar O, Mete N, Cicek C, Basoglu OK, Sin A, Kokuludag A: Chlamydia pneumoniae arthritis in a patient with common variable immunodeficiency. Ann Allergy Asthma Immunol 2005, 94:504-508.

8. Balin BJ, Little CS, Hammond CJ, Appelt DM, Whittum-Hudson JA, Gerard HC, Hudson AP: Chlamydophila pneumoniae and the etiology of late-onset Alzheimer's disease. J Alzheimers Dis 2008, I 3:37|-380.

9. Gerard HC, Dreses-Werringloer U, Wildt KS, Deka S, Oszust C, Balin BJ, Frey WH, Bordayo EZ, Whittum-Hudson JA, Hudson AP: Chlamydophila (Chlamydia)pneumoniae in the Alzheimer's brain. FEMS Immunol Med Microbiol 2006, 48:355-366.

10. Contini C, Seraceni S, Cultrera R, Castellazzi M, Granieri E, Fainardi E: Molecular detection of Parachlamydia-like organisms in cerebrospinal fluid of patients with multiple sclerosis. Mult Scler 2008, 14:564-566.

II. Fainardi E, Castellazzi M, Seraceni S, Granieri E, Contini C: Under the Microscope: Focus on Chlamydia pneumoniae Infection and Multiple Sclerosis. Curr Neurovasc Res 2008, 5:60-70.

12. Munger KL, Peeling RW, Hernan MA, Chasan-Taber L, Olek MJ, Hankinson SE, Hunter D, Ascherio A: Infection with Chlamydia pneumoniae and risk of multiple sclerosis. Epidemiology 2003, | 4: $|4|-147$

13. Stratton CW, Wheldon DB: Multiple sclerosis: an infectious syndrome involving Chlamydophila pneumoniae. Trends Microbiol 2006, I 4:474-479.

14. Gaydos CA, Summersgill JT, Sahney NN, Ramirez JA, Quinn TC: Replication of Chlamydia pneumoniae in vitro in human macrophages, endothelial cells, and aortic artery smooth muscle cells. Infect Immun 1996, 64: I6 |4-1620.

15. Yamaguchi H, Haranaga S, Friedman H, Moor JA, Muffly KE, Yamamoto Y: A Chlamydia pneumoniae infection model using established human lymphocyte cell lines. FEMS Microbiol Lett 2002, 2 I 6:229-234.

16. Yamaguchi H, Friedman H, Yamamoto M, Yasuda K, Yamamoto Y: Chlamydia pneumoniae resists antibiotics in lymphocytes. Antimicrob Agents Chemother 2003, 47:1972-1975.

17. Gieffers J, van Zandbergen G, Rupp J, Sayk F, Kruger S, Ehlers S, Solbach W, Maass M: Phagocytes transmit Chlamydia pneumoniae from the lungs to the vasculature. Eur Respir J 2004, 23:506-5 I 0.

18. Zele-Starcevic L, Plecko V, Budimir A, Kalenic S: [Choice of antimicrobial drug for infections caused by Chlamydia trachomatis and Chlamydophila pneumoniae]. Acta Med Croatica 2004, 58:329-333.

19. Misyurina OY, Chipitsyna EV, Finashutina YP, Lazarev VN, Akopian TA, Savicheva AM, Govorun VM: Mutations in a 23S rRNA gene of Chlamydia trachomatis associated with resistance to macrolides. Antimicrob Agents Chemother 2004, 48: I 347- 1349.

20. Binet R, Maurelli AT: Frequency of spontaneous mutations that confer antibiotic resistance in Chlamydia spp. Antimicrob Agents Chemother 2005, 49:2865-2873.

21. Binet R, Maurelli AT: Frequency of development and associated physiological cost of azithromycin resistance in Chlamydia psittaci 6BC and C. trachomatis L2. Antimicrob Agents Chemother 2007, 5 I:4267-4275.

22. Dugan J, Andersen AA, Rockey DD: Functional characterization of IScs605, an insertion element carried by tetracyclineresistant Chlamydia suis. Microbiology 2007, I 53:7I-79.

23. Kutlin A, Kohlhoff S, Roblin P, Hammerschlag MR, Riska P: Emergence of resistance to rifampin and rifalazil in Chlamydophila 
pneumoniae and Chlamydia trachomatis. Antimicrob Agents Chemother 2005, 49:903-907.

24. Rupp J, Solbach W, Gieffers J: Variation in the mutation frequency determining quinolone resistance in Chlamydia trachomatis serovars L2 and D. J Antimicrob Chemother 2008, 61:91-94.

25. Shkarupeta MM, Lazarev VN, Akopian TA, Afrikanova TS, Govorun VM: Analysis of antibiotic resistance markers in Chlamydia trachomatis clinical isolates obtained after ineffective antibiotic therapy. Bull Exp Biol Med 2007, I43:7|3-7I7.

26. Gieffers J, Rupp J, Gebert A, Solbach W, Klinger M: First-choice antibiotics at subinhibitory concentrations induce persistence of Chlamydia pneumoniae. Antimicrob Agents Chemother 2004, 48: I 402-I 405.

27. Reveneau N, Crane DD, Fischer E, Caldwell HD: Bactericida activity of first-choice antibiotics against gamma interferoninduced persistent infection of human epithelial cells by Chlamydia trachomatis. Antimicrob Agents Chemother 2005, 49:1787-1793.

28. Wyrick PB, Knight ST: Pre-exposure of infected human endometrial epithelial cells to penicillin in vitro renders Chlamydia trachomatis refractory to azithromycin. J Antimicrob Chemother 2004, 54:79-85.

29. Migliorini L, Canocchi V, Zanelli G, Valassina M, Cellesi C: Outbreak and persistence of Chlamydia pneumoniae infection in an Italian family. Infez Med 2003, I I:157-160.

30. Mpiga $\mathrm{P}$, Ravaoarinoro M: Chlamydia trachomatis persistence: an update. Microbiol Res 2006, I6I:9-19.

31. Davis $\mathrm{CH}$, Raulston JE, Wyrick PB: Protein disulfide isomerase, a component of the estrogen receptor complex, is associated with Chlamydia trachomatis serovar $\mathbf{E}$ attached to human endometrial epithelial cells. Infect Immun 2002, 70:34|3-34I8.

32. Hackstadt T, Todd WJ, Caldwell HD: Disulfide-mediated interactions of the chlamydial major outer membrane protein: role in the differentiation of chlamydiae? J Bacteriol 1985, 16 I:25-3 I.

33. Raulston JE, Davis CH, Paul TR, Hobbs JD, Wyrick PB: Surface accessibility of the 70-kilodalton Chlamydia trachomatis heat shock protein following reduction of outer membrane protein disulfide bonds. Infect Immun 2002, 70:535-543.

34. Mannonen L, Kamping E, Penttila T, Puolakkainen M: IFN-gamma induced persistent Chlamydia pneumoniae infection in HL and Mono Mac 6 cells: characterization by real-time quantitative PCR and culture. Microb Pathog 2004, 36:4I-50.

35. Shaw EI, Dooley CA, Fischer ER, Scidmore MA, Fields KA, Hackstadt $\mathrm{T}$ : Three temporal classes of gene expression during the Chlamydia trachomatis developmental cycle. Mol Microbiol 2000, 37:913-925.

36. Wilson DP, Mathews S, Wan C, Pettitt AN, McElwain DL: Use of a quantitative gene expression assay based on micro-array techniques and a mathematical model for the investigation of chlamydial generation time. Bull Math Biol 2004, 66:523-537.

37. Hybiske K, Stephens RS: Mechanisms of host cell exit by the intracellular bacterium Chlamydia. Proc Natl Acad Sci USA 2007, 104: I 430-I| 435

38. Raulston JE: Response of Chlamydia trachomatis serovar $\mathbf{E}$ to iron restriction in vitro and evidence for iron-regulated chlamydial proteins. Infect Immun 1997, 65:4539-4547.

39. Bailey L, Gylfe A, Sundin C, Muschiol S, Elofsson M, Nordstrom $P$, Henriques-Normark B, Lugert R, Waldenstrom A, Wolf-Watz $\mathrm{H}$ Bergstrom S: Small molecule inhibitors of type III secretion in Yersinia block the Chlamydia pneumoniae infection cycle. FEBS Lett 2007, 58 I:587-595.

40. Shivshankar P, Lei L, Wang J, Zhong G: Rottlerin inhibits chlamydial intracellular growth and blocks chlamydial acquisition of sphingolipids from host cells. Appl Environ Microbiol 2008, 74:1243-1249.

4I. Wolf K, Betts HI, Chellas-Gery B, Hower S, Linton CN, Fields KA: Treatment of Chlamydia trachomatis with a small molecule inhibitor of the Yersinia type III secretion system disrupts progression of the chlamydial developmental cycle. Mol Microbiol 2006, 61: I543-1555.

42. Yan Y, Silvennoinen-Kassinen S, Tormakangas L, Leinonen M, Saikku $P$ : Selective cyclooxygenase inhibitors prevent the growth of Chlamydia pneumoniae in HL cells. Int J Antimicrob Agents 2008, 32:78-83.
43. Coombes BK, Mahony JB: Identification of MEK- and phosphoinositide 3-kinase-dependent signalling as essential events during Chlamydia pneumoniae invasion of HEp2 cells. Cell Microbiol 2002, 4:447-460.

44. Muschiol S, Bailey L, Gylfe A, Sundin C, Hultenby K, Bergstrom S, Elofsson M, Wolf-Watz H, Normark S, Henriques-Normark B: A smallmolecule inhibitor of type III secretion inhibits different stages of the infectious cycle of Chlamydia trachomatis. Proc Natl Acad Sci USA 2006, 103: | 4566- |457|

45. Johnson DL, Mahony JB: Chlamydophila pneumoniae PknD exhibits dual amino acid specificity and phosphorylates Cpn07 I 2, a putative type III secretion YscD homolog. I Bacteriol 2007, I 89:7549-7555.

46. Mahony JB, Johnson DL, Coombes BK, Song X: Expression of a Novel Protein Kinase Gene (Cpn0I48) During the Replication Cycle of Chlamydia pneumoniae. In Chlamydial Infections, International Symposium on Human Chlamydial Infections Volume 10. Edited by: Schachter J, Christiansen G, Clarke I. Antalya, Turkey. International Chlamydia Symposium, San Francisco, CA; 2002:559-562

47. Stone CB, Johnson DL, Bulir DC, Gilchrist JD, Mahony JB: Characterization of the putative type III secretion ATPase CdsN (Cpn0707) of Chlamydophila pneumoniae. J Bacteriol 2008, 190:6580-6588.

48. Su H, McClarty G, Dong F, Hatch GM, Pan ZK, Zhong G: Activation of Raf/MEK/ERK/cPLA2 signaling pathway is essential for chlamydial acquisition of host glycerophospholipids. I Biol Chem 2004, 279:9409-9416.

49. Gurniak $C B$, Berg LI: Murine JAK3 is preferentially expressed in hematopoietic tissues and lymphocyte precursor cells. Blood 1996, 87:3I5I-3160.

50. Rane SG, Reddy EP: JAK3: a novel JAK kinase associated with terminal differentiation of hematopoietic cells. Oncogene 1994, 9:24I5-2423.

5I. Tortolani PJ, Lal BK, Riva A, Johnston JA, Chen YQ, Reaman GH, Beckwith M, Longo D, Ortaldo JR, Bhatia K, McGrath I, Kehrl J, Tuscano J. McVicar DW, O'Shea J]: Regulation of JAK3 expression and activation in human $B$ cells and $B$ cell malignancies. J Immunol 1995, 155:5220-5226.

52. Lad SP, Fukuda EY, Li J, de la Maza LM, Li E: Up-regulation of the JAK/STATI signal pathway during Chlamydia trachomatis infection. J Immunol 2005, I 74:7186-7|93.

53. Bain J, McLauchlan H, Elliott M, Cohen P: The specificities of protein kinase inhibitors: an update. Biochem J 2003, 371: 199-204.

54. Bain J, Plater L, Elliott M, Shpiro N, Hastie C], McLauchlan H, Klevernic I, Arthur JS, Alessi DR, Cohen P: The selectivity of protein kinase inhibitors: a further update. Biochem J 2007. 408:297-3I5

55. Davies SP, Reddy H, Caivano M, Cohen P: Specificity and mechanism of action of some commonly used protein kinase inhibitors. Biochem J 2000, 35 I:95-105.

56. Wray C, Sojka WJ: Experimental Salmonella typhimurium infection in calves. Res Vet Sci 1978, 25:139-143.

57. Mohler WA, Charlton CA, Blau HM: Spectrophotometric quantitation of tissue culture cell number in any medium. Biotechniques 1996, 21:260-2, 264, 266.

Publish with Bio Med Central and every scientist can read your work free of charge

"BioMed Central will be the most significant development for disseminating the results of biomedical research in our lifetime. "

Sir Paul Nurse, Cancer Research UK

Your research papers will be:

- available free of charge to the entire biomedical community

- peer reviewed and published immediately upon acceptance

- cited in PubMed and archived on PubMed Central

- yours - you keep the copyright 